\title{
Reaction of Soybean Cultivars to Isolates of Fusarium solani from the Red River Valley
}

\author{
Berlin D. Nelson and Jana M. Hansen, Department of Plant Pathology, North Dakota State University, Fargo, \\ 58105; Carol E. Windels, Northwest Experiment Station, University of Minnesota, Crookston, 56716; and Ted C. \\ Helms, Department of Plant Sciences, North Dakota State University, Fargo 58105
}

\begin{abstract}
Nelson, B. D., Hansen, J. M., Windels, C. E., and Helms, T. C. 1997. Reaction of soybean cultivars to isolates of Fusarium solani from the Red River Valley. Plant Dis. 81:664-668.

Five isolates of Fusarium solani, originally isolated from diseased soybean roots in the Red River Valley (RRV) of Minnesota and North Dakota, were evaluated for their ability to cause symptoms on 10 genetically diverse soybean cultivars. Taproots of 2-week-old plants were inoculated with $F$. solani-infested oat kernels, and 3 and 10 weeks later, plants were evaluated for root rot and foliar symptoms. At 3 weeks after inoculation, taproots of all cultivars had extensive reddish brown to black lesions; root rot severity (1-6 scale) ranged from 4.8 to 5.1, and $3.5 \%$ of the plants had died. Foliar symptoms were not observed. At 10 weeks after inoculation, all cultivars showed extensive decay of taproots and $>50 \%$ of lateral roots were necrotic; root rot severity (1-4 scale) ranged from 2.7 to 3.7 , and $42.5 \%$ of the plants had died. Foliar symptoms were first observed between the R-1 to R-6 growth stages (about 5 weeks after inoculation) on the lower leaves and consisted of chlorosis at the margins that progressed inward. Veins initially were green, but leaves eventually became chlorotic, then necrotic, and fell with petioles still attached to the stem. In some cases, all of the foliage died. There was no significant $(P=$ 0.05 ) isolate $\times$ cultivar interaction for root rot at 3 or 10 weeks after inoculation or for severity of foliar symptoms. Thirty-three cultivars commonly grown in southern Minnesota and the RRV were evaluated for reaction to one isolate of $F$. solani. Root rot severity ranged from 4.2 to 5.7 (1-6 scale) and 3.5 to 4.0 (1-4 scale), at 3 and 9 weeks after inoculation, respectively, and $>50 \%$ of the plants died by 9 weeks after inoculation. Severity of foliar symptoms was low. These results indicate that isolates of $F$. solani from the RRV cause root rot and foliar symptoms on soybean and that cultivars grown in the region lack resistance to this pathogen. Foliar symptoms were not identical to those associated with sudden death syndrome.
\end{abstract}

Additional keywords: foliar symptoms, Glycine max, Minnesota, North Dakota, root rot

Soybean (Glycine max L.) has become a popular crop in the Red River Valley (RRV) of Minnesota and North Dakota with approximately 354,000 ha currently planted. Root rots caused by Fusarium species, Phytophthora sojae M. J. Kaufmann \& J. W. Gerdeman, and Rhizoctonia solani Kühn are increasing in importance (14-16). When soybean crops are in 1- to 2 -yr rotations or are rotated with sugar beet or dry bean, root rots have caused serious losses (personal observations). Nelson and Windels (16) reported that $10 \%$ of 476 Fusarium isolates from soybean roots collected in the RRV were $F$. solani (Mart.) Appel \& Wollenweb. emend. Snyd. \& Hans; 23 of 32 isolates inoculated on soybean caused discoloration and decay of taproots. In a 1963 report from Minnesota, French and Kennedy (6) isolated F. solani

Corresponding author: Berlin D. Nelson

E-mail: bernelso@plains.nodak.edu

Accepted for publication 9 March 1997.

Publication no. D-1997-0326-04R

(C) 1997 The American Phytopathological Society from soybean roots collected in central and southern Minnesota, but those isolates were not pathogenic. Although other researchers also have reported $F$. solani to cause root rot of soybean $(10,11,18,26)$, most interest in this pathogen has focused on sudden death syndrome (SDS) $(8,11,13,18,19,21)$. There have been few in-depth studies on the biology or importance of root rot of soybean caused by isolates of $F$. solani that do not cause SDS $(10,11,18$.

SDS was first observed in Arkansas in 1971 (19) but has since been reported in Alabama, Illinois, Indiana, Iowa, Kansas, Kentucky, Mississippi, Missouri, and Tennessee $(5,7,13,19,25)$. Major symptoms of SDS include root rot, crown necrosis, and vascular discoloration of roots and stems, but leaf symptoms are the most conspicuous phase of the disease $(18,19)$. These include interveinal chlorosis and necrosis, defoliation, and pod abortion. Foliar symptoms of SDS usually appear during the early- to mid-reproductive growth stages as scattered interveinal, chlorotic spots that become necrotic and coalesce. The tissues adjacent to the major veins often remain green during symptom devel- opment $(18,19)$. SDS is ranked the ninth most important disease of soybean in the northcentral United States (4).

Symptoms typical of SDS have not been reported in the RRV, although root rot caused by $F$. solani has been observed (personal observations). While the extent of losses from Fusarium root rot are unknown, the high percentage of pathogenic isolates from soybean (16) in the RRV suggests that $F$. solani may be an important pathogen. Cultivars adapted to Minnesota and North Dakota have not been tested for resistance to $F$. solani. The objectives of this research were to ascertain symptoms produced by $F$. solani, determine if there is an interaction between $F$. solani isolate and soybean cultivar, and evaluate commercial soybean cultivars commonly grown in southern Minnesota and the RRV for reaction to F. solani in the greenhouse.

\section{MATERIALS AND METHODS}

Cultivars and greenhouse procedures. Symptoms caused by $F$. solani and interactions of isolates with soybean cultivars were studied on plants inoculated at 2 weeks of age and evaluated for disease 3 and 10 weeks later in separate experiments. Ten cultivars were selected to evaluate disease 3 weeks after inoculation. These cultivars (followed by their maturity groups) were as follows: Bicentennial (00), Evans (0), Hardin (I), Kato (I), Maple Amber (00), Maple Isle (00), McCall (00), Parker (I), Pioneer 9061 (0), and Proto (0). Ten different cultivars were selected to evaluate disease at 10 weeks after inoculation: Baker (0), Dawson (0), Evans (0), Hunter (0), Jacques 009 (0), Lambert (0), McCall (00), Ozzie (0), Pioneer 9061 (0), and Pioneer 9091 (0). These two groups of cultivars were chosen because they represented a broad genetic background of cultivars and thus would allow a more accurate evaluation of symptom development and interaction of cultivar $\times$ isolate of $F$. solani.

Soybean seeds were surface-treated in $0.5 \% \mathrm{NaOCl}$ for $30 \mathrm{~s}$ and planted in pasteurized $\left(65^{\circ} \mathrm{C}\right.$ for $2 \mathrm{~h}$ ) soil mix (equal parts of Glyndon sandy loam, \#2 vermiculite, and peat moss) contained in $15.5-\mathrm{cm}$ diameter clay pots. Pots were over-seeded and, after seedling emergence, thinned to four plants per pot. Plants were watered daily and fertilized weekly (except 4 days before and after inoculation) with $0.4 \mathrm{~g}$ of 
Peters 20-20-20 (N-P-K) plus $0.01 \mathrm{~g}$ of an iron chelate per pot. Plants were watered daily to ensure high soil moisture after inoculations. Illumination was obtained with high-pressure sodium lamps $(1,000$ $\left.\mu \mathrm{E} \cdot \mathrm{m}^{-2} \cdot \mathrm{s}^{-1}\right)$ for $16 \mathrm{~h}$ per day. Experiments to evaluate disease 3 weeks after inoculation were conducted in the summer where greenhouse temperatures ranged from 18 to $32^{\circ} \mathrm{C}$ with an average of $25^{\circ} \mathrm{C}$. Experiments to evaluate disease 10 weeks after inoculation were conducted in the fall and winter when temperatures ranged from 15 to $30^{\circ} \mathrm{C}$ and averaged $22^{\circ} \mathrm{C}$.

The experimental design was a randomized split plot with isolates as whole plots and cultivars as split plots with five replicates. An experimental unit consisted of one pot containing four plants. Disease severities were averaged among plants within experimental units. All experiments were repeated.

Thirty-three commercial soybean cultivars commonly grown in Minnesota and North Dakota were tested for reaction to an aggressive isolate of $F$. solani. Cultivars ranged in maturity groups from 00 to II and were inoculated at 2 weeks of age. Disease evaluations were made 3 and 9 weeks after inoculation in separate experiments. One cultivar, Pioneer 9181, was not included in the evaluation at 3 weeks after inoculation. Planting and greenhouse procedures were as previously described. Experiments to evaluate disease at 3 and 9 weeks after inoculation were conducted between March and June and from May to September, respectively. In tests where disease was assessed 3 weeks after inoculation, the cultivars commonly grown in North Dakota and northern Minnesota were in experiments separate from cultivars grown in southern Minnesota. All of these cultivars, however, were in the same experiments when disease was assessed at 9 weeks after inoculations. The experimental design was a randomized block with five replicates. Experimental units and averaging of disease severities were as previously described. All experiments were repeated.

Inoculations. Five isolates of $F$. solani that exhibited a range of cultural characteristics were used to examine symptom development and cultivar $\times$ isolate interactions. The isolates were obtained from diseased soybean roots collected in the RRV and were selected based on previous pathogenicity tests (16). Isolates were designated 11-2-A, 31-2-F, 115-3-A, 1991-E, and 78-2-E. In experiments to evaluate disease at 10 weeks, isolate $10-1-\mathrm{G}$ was substituted for 199-1-E. The letter designation for each isolate refers to specific cultural characteristics observed on homemade acidified potato dextrose agar (PDA) when cultures were originally isolated, hyphal tipped, and identified: $\mathrm{A}=$ blue centers with slimy pionnotal masses of macroconidia and few microconidia, sparse white to gray mycelium on edges of colony, white to brown concentric rings, and on the reverse side of the colony the agar stained a dark reddish brown to maroon; E $=$ flocculose mycelium with tan center to colony and white mycelium on edges plus slightly raised concentric rings, macro- and microconidia present; $\mathrm{F}=$ white to pale yellow flocculose aerial mycelium, no concentric rings, macro- and microconidia present; and $\mathrm{G}=$ brown to $\tan$ flocculose aerial mycelium, no concentric rings and a brown to pink tinge to agar, macro- and microconidia present.

Cultures were stored at $-80^{\circ} \mathrm{C}$ on carnation leaves or barley grains and were revived by placing the tissue on Difco PDA for $48 \mathrm{~h}$ and then transferring mycelium to fresh PDA. Inoculum was prepared by growing cultures on PDA for 2 days at 25 $\pm 2{ }^{\circ} \mathrm{C}$ under cool white and nearultraviolet light on a 12-h light/dark cycle. Oat kernels were placed in water for $1 \mathrm{~h}$, autoclaved for $90 \mathrm{~min}$, cooled, and then 50 kernels were spread over the 2-day-old mycelia per petri plate. Cultures were incubated for an additional 14 days under the same conditions. Plants were inoculated by pressing four infested oat kernels next to the taproot, approximately $1.5 \mathrm{~cm}$ below the soil surface (21). Soil was placed over the kernels and gently pressed into place. Controls were inoculated with autoclaved oat kernels.

The 33 commercial soybean cultivars were inoculated with isolate 115-3-A. In previous pathogenicity tests, this isolate had resulted in consistently high disease ratings. Preparation of inoculum and method of inoculation were as previously described, with the exception that the taproots were inoculated with three oat kernels instead of four. During the course of these experiments, the effectiveness of the number of oat kernels was tested, and three kernels produced root rot severities similar to four kernels (unpublished data).

Evaluation criteria. For plants evaluated 3 weeks after inoculations, roots were gently washed in running tap water to remove all soil. Disease severity on taproots was determined using a scale of 1-6 where $1=$ no disease on taproot, $2=$ lesions $<5$ $\mathrm{mm}$ or $<25 \%$ girdling, $3=$ lesions $5-10$ $\mathrm{mm}$ or $25-50 \%$ girdling, $4=$ lesions $10-15$ $\mathrm{mm}$ or $50-75 \%$ girdling, $5=$ lesions $>15$ $\mathrm{mm}$ or $>75 \%$ girdling, and $6=$ roots rotted and $75 \%$ of leaves wilted or plant dead.

For plants evaluated at 9 or 10 weeks after inoculation, foliar symptoms were assessed using a $0-5$ scale (19) where $0=$ no symptoms, $1=1-10 \%$ of foliage with chlorosis and/or necrosis, $2=11-30 \%, 3=$ $31-70 \%, 4=71-90 \%$, and $5=91-100 \%$. To determine when symptoms appeared, plants were observed weekly and development of foliar symptoms was recorded. Roots were then gently washed in running tap water and the entire root mass was rated for root rot on a $1-4$ scale where $1=$
$0-24 \%$ of the roots necrotic, $2=25-49 \%$, $3=50-74 \%$, and $4=75-100 \%$. This scale was chosen over the root rot scale used at 3 weeks, because extensive rot of lateral roots developed over the 9- to 10-week period. Plants that died during the experiments were immediately rated for root rot.

Random samples were chosen in each experiment for reisolation of the pathogen. One-centimeter sections of stems with lesions were surface-treated in $0.5 \%$ $\mathrm{NaOCl}$ for $30 \mathrm{~s}$ and placed on water agar containing streptomycin sulfate (120 $\mathrm{mg} / \mathrm{L}$ ). After 3 days, cultures were transferred to PDA and incubated under lights as previously described. Identification of $F$. solani was based on colony morphology and characteristics of the conidia $(17,24)$.

Statistical analysis. Analysis of variance was performed on all data. Homogeneity of variance was determined for similar experiments and data were combined for analysis when variances were homogeneous. In experiments examining interactions, cultivars and isolates were consid-
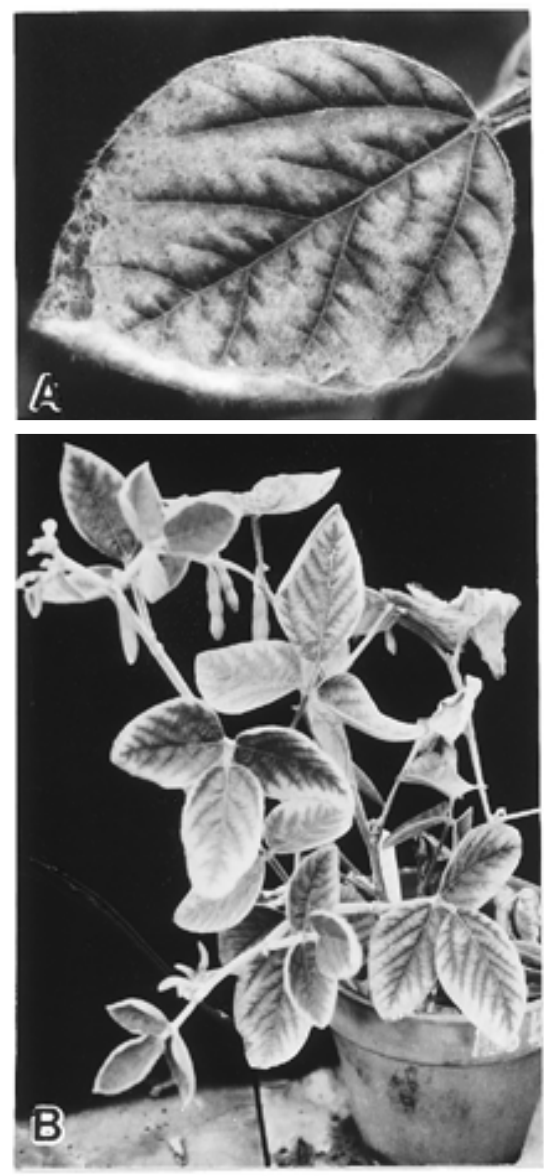

Fig 1. Soybean with foliar symptoms caused by a root rot isolate of Fusarium solani. This 8week-old plant was inoculated with $F$. solaniinfested oat kernels that were placed against the taproot 2 weeks after planting. (A) Chlorosis starting at the leaf edge and progressing inward; veins remained green for 1-3 weeks. (B) Entire plant with chlorotic leaves; leaves eventually became completely chlorotic, dried up and fell, leaving the petioles attached to the stem. 
ered fixed effects, whereas experiments were considered random effects.

\section{RESULTS}

Disease assessment at 3 weeks. By 3 weeks after inoculation, $F$. solani caused extensive reddish brown to black lesions (often with distinct reddish brown margins) on taproots of all cultivars. Necrotic tissue extended into the cortex. Foliar symptoms were not observed, and there was no distinct discoloration in stem tissue. Variances between the two experiments were not homogeneous; therefore, data were not pooled for analysis. Isolate and cultivar were not significant $(P=0.05)$ factors in either experiment, and there were no significant $(P=0.05)$ isolate $\times$ cultivar interactions (data not shown). Root rot severities, therefore, were averaged over isolates within experiments. Root rot severities among cultivars averaged 5.0 (range 5.05.1) and 4.9 (range 4.8-5.1) in experiments $\mathrm{A}$ and $\mathrm{B}$, respectively (data not shown). Of the total number of plants in the two experiments, $3.5 \%$ died from root rot. The controls remained healthy. $F$. solani was consistently reisolated from diseased cortical tissue in taproots.

Disease assessment at 10 weeks. $F$. solani caused black lesions on roots of all cultivars. The lesions often girdled and covered $>50 \%$ of the taproot. Necrotic tissue extended into the cortex near the steel, and fissures in the necrotic surfaces of taproots were common. There was extensive decay $(>50 \%)$ of the lateral roots of most cultivars.

Foliar symptoms occurred on all cultivars, but severity was low. Symptoms began in the lower leaves and first appeared in some cultivars about 5 weeks after inoculation. Cultivars ranged from the R-1 to R-6 growth stage (20) when symptoms first appeared. At 10 weeks after inoculation, cultivars ranged between the R-3 and R-6 growth stages. Symptoms consisted of chlorosis starting at the leaf edges and progressing inward (Fig. 1A). Veins remained green for one to several weeks. The leaves eventually became completely chlorotic, then necrotic, and dried up and fell, leaving the petioles attached to the stem. On some plants, all foliage became chlorotic then necrotic (Fig. 1B). There was no consistent, distinct discoloration in stems and petioles. These symptoms were not observed in the controls.

Data on root rot, foliar disease, and number of living plants per pot were combined over experiments for analysis. The average root rot and foliar disease severity, and number of living plants per pot were $3.4,1.2$, and 2.3 , respectively (Table 1 ). There was no significant effect $(P=0.05)$ of isolate or cultivar on root rot, foliar disease severity, or on number of living plants per pot, and there was no significant $(P=0.05)$ isolate $\times$ cultivar interaction. Data, therefore, were combined over isolates (Table 1).

There were significant interactions for experiment $\times$ isolate $(P=0.05)$ for root rot and foliar symptoms, and experiment $\times$ cultivar $(P=0.001)$ for root rot, foliar symptoms, and number of living plants per pot in the analysis of combined data. In the analysis of variances of individual experiments, there was a significant $(P=0.05)$ effect of cultivar on root rot, foliar disease severity, and number of living plants per pot, thus the data from each experiment are presented along with the combined data (Table 1). Cultivars did not rank the same between experiments for any of the three measurements; however, the differences, although significant, were small. There was no significant effect of isolate in the first experiment, however, in the second experiment, isolate had a significant $(P=$ 0.05 ) effect on root rot and foliar disease severities, but the differences were small (data not shown). For example, isolates 112-A and 31-2-F, which were significantly different from each other, had severity ratings of 3.1 and 3.7 for root rot and 0.6 and 1.1 for foliar disease, respectively. There also was a significant effect of experiment for foliar symptoms $(P=0.01)$ and number of living plants per pot $(P=$ 0.001 ) due to a greater disease severity in the first experiment; foliar disease severity and number of living plants per pot, averaged over all cultivars, were both 1.6 in experiment A and 0.9 and 3.0, respectively, in experiment $\mathrm{B}$.

$F$. solani substantially reduced the number of living plants when compared with the controls (all controls survived). When averaged over experiments and cultivars, the mean number of living plants per pot in the controls and inoculated treatments was 4 and 2.3 , respectively, a $42.5 \%$ decrease in living plants at 10 weeks after inoculation. More plants died in the first than in the second, experiment (mean of 1.6 and 3.0 living plants per pot, respectively). $F$. solani was consistently reisolated from diseased root tissue.

Disease assessment of commercial cultivars. For the commercial cultivars evaluated 3 weeks after inoculation, there were no differences in root rot severities among the southern Minnesota cultivars (Table 2). Among cultivars grown in the RRV of North Dakota and northern Minnesota, there were significant $(P=0.05)$ differences in root rot severity in the first, but not the second experiment (Table 2). Root rot severity among all cultivars was high, ranging from 4.2 to 5.7. Foliar symptoms were not observed. Among the cultivars grown in North Dakota and northern Minnesota, 10 and $27 \%$ of the inoculated plants died in the first and second experiments, respectively. Among the southern Minnesota cultivars, only 3.5 and $2 \%$ of the plants died in the first and second experiments, respectively. Experiments with RRV cultivars were conducted between March and April and

Table 1. Effects of Fusarium solani on root rot, foliar symptoms, and number of living plants at 10 weeks after inoculation of 2-week-old soybean culti$\operatorname{vars}^{\mathrm{z}}$

\begin{tabular}{|c|c|c|c|c|c|c|c|c|c|}
\hline \multirow[b]{3}{*}{ Cultivar } & \multicolumn{6}{|c|}{ Disease severity } & & & \\
\hline & \multicolumn{3}{|c|}{ Root rot } & \multicolumn{3}{|c|}{ Foliar } & \multicolumn{3}{|c|}{ Living plants per pot } \\
\hline & $\operatorname{Exp} A$ & Exp B & Combined & $\operatorname{Exp} A$ & $\operatorname{Exp} B$ & Combined & $\operatorname{Exp} A$ & $\operatorname{Exp} B$ & Combined \\
\hline Pioneer 9091 & 3.8 & 3.6 & 3.7 & 2.6 & 1.3 & 1.9 & 1.2 & 2.6 & 1.9 \\
\hline Evans & 3.8 & 3.4 & 3.6 & 2.1 & 0.9 & 1.5 & 1.4 & 3.0 & 2.2 \\
\hline Lambert & 3.6 & 3.5 & 3.5 & 1.8 & 1.2 & 1.5 & 1.9 & 3.3 & 2.6 \\
\hline Pioneer 9061 & 3.5 & 3.5 & 3.5 & 1.1 & 0.8 & 0.9 & 2.1 & 3.1 & 2.6 \\
\hline Ozzie & 3.6 & 3.4 & 3.5 & 2.0 & 0.7 & 1.3 & 2.1 & 3.0 & 2.5 \\
\hline Dawson & 3.7 & 3.2 & 3.4 & 1.9 & 0.7 & 1.3 & 2.3 & 2.9 & 2.6 \\
\hline Baker & 3.5 & 3.3 & 3.4 & 1.9 & 0.5 & 1.2 & 1.8 & 3.3 & 2.6 \\
\hline Hunter & 3.0 & 3.6 & 3.3 & 0.9 & 0.9 & 0.9 & 1.7 & 2.7 & 2.2 \\
\hline Jacques 009 & 3.1 & 3.2 & 3.2 & 1.5 & 0.8 & 1.2 & 0.6 & 3.5 & 2.1 \\
\hline McCall & 2.0 & 3.4 & 2.7 & 0.4 & 0.9 & 0.7 & 0.6 & 2.9 & 1.8 \\
\hline $\operatorname{LSD}(P=0.05)$ & 0.4 & 0.3 & NS & 0.6 & 0.4 & NS & 0.8 & 0.5 & NS \\
\hline
\end{tabular}

${ }^{\mathrm{z}}$ Data from two experiments (Exp) and the combined data are presented. Plants were inoculated on taproots with oat kernel inoculum of five isolates of $F$. solani. Root rot severity (1-4 scale, where $1=0-24 \%$ and $4=75-100 \%$ of root mass dead), severity of foliar symptoms $(0-5$ scale, $0=$ no symptoms and $5=91-100 \%$ of foliage with symptoms), and the number of living plants per pot were determined 10 weeks after inoculation. There was no significant $(P=0.05)$ cultivar $\times$ isolate interaction so data was combined over five isolates. Cultivars are ranked according to root rot severity in the combined data. All cultivars are in maturity group 0 . 
those with the southern cultivars between April and June.

For the commercial cultivars evaluated 9 weeks after inoculation, there were no differences in severity of root rot or foliar symptoms in either experiment (data not shown). Cultivars in the two experiments ranged from the R-3 to R-6 growth stage. All cultivars had high levels of root rot severity ranging from 3.5 to 4.0 . Severity of foliar symptoms was low, ranging from 0 to 1.6 ; symptoms first appeared between 4 and 5 weeks after inoculation. There was a significant $(P=0.05)$ difference among cultivars in the number of living plants per pot in the first experiment (range 0.4 [Jacques 009] to 3.6 [Stine 0380]), but not in the second experiment (range 1.4-2.4). Of the total inoculated plants, 66 and 52\% died in the first and second experiments, respectively. Four of the early maturity cultivars (Hunter, KG-20, Maple Ridge, and McCall) began senescing prior to the evaluation date, so no data on foliar symptoms or living plants were included in the analysis. These four cultivars showed low levels of foliar symptoms ranging from 0.3 to 1.5 when senescence began. These cultivars were rated for root rot severity after the initiation of senescence.

\section{DISCUSSION}

This research shows that isolates of $F$. solani from the Red River Valley cause severe root rot, foliar symptoms, and death of soybean plants, and thus may be more important than previously realized in the Minnesota-North Dakota region. F. solani was previously reported from soybean roots in central and southern Minnesota $(6,23)$, but French and Kennedy (6) found that isolates were nonpathogenic in greenhouse trials. French and Kennedy (6) also reported $F$. oxysporum as the predominant pathogen of soybean roots in Minnesota. Nelson and Windels (16), however, found $F$. oxysporum was the most common Fusarium species isolated from roots, but isolates were either weakly pathogenic or nonpathogenic. In contrast, nearly all isolates of $F$. solani were highly pathogenic.

The foliar symptoms reported here appear to be associated with general symptoms of root rot. Other researchers studying the pathogenicity of non-SDS isolates of $F$. solani on soybean have reported damping-off and root rot but not foliar symptoms associated with disease $(10,11,18)$. Foliar symptoms observed here were not identical to those reported for SDS. Foliar symptoms of SDS begin with chlorotic mottling and proceed with interveinal chlorosis and necrosis $(18,19)$. Symptoms observed in this study always began on the edges as chlorosis and progressed inward interveinally then becoming necrotic. In advanced stages of leaf symptoms, where there was chlorosis or necrosis and green veins, leaves appeared similar to the symptoms reported for SDS
$(18,19)$. It was due to these advanced foliar symptoms caused by two blue isolates of $F$. solani (isolates 115-3-A and 11-2-A) that Nelson and Windels (16), in a preliminary report, incorrectly stated that some isolates of $F$. solani from the RRV caused symptoms typical of SDS. These two isolates had some of the cultural characteristics of the FS-A or blue isolates of F. solani reported to cause SDS $(18,19)$.

Severity of foliar symptoms in all experiments was low, but some plants developed a striking chlorosis of the entire foliage followed by death of the plant. These symptoms were most commonly seen with isolate 115-3-A. They did not occur consistently in each experiment and were common during cool periods in the greenhouse. These symptoms occurred before the taproots or lateral roots were completely destroyed by root rot. This systemic chlorosis suggests a toxin in disease development, but there are no reports of toxins involved in the pathogenesis of non-SDS isolates of $F$. solani on soybean. F. solani produces a variety of toxins and two, the proteinaceous toxin monorden and a polypeptide toxin, are produced by isolates of $F$. solani that cause SDS $(1,2,8,9)$

The severity of root rot on both young and older plants, plus the large number of older plants that were killed, shows that isolates of $F$. solani from the RRV are highly aggressive under greenhouse conditions. Although the number of isolates tested was small, they varied in origin and represented a range of cultural characteristics typical of isolates found in the RRV. Because there was no isolate $\times$ cultivar interaction, screening for resistance to root rot caused by $F$. solani could be conducted with one highly aggressive isolate. There have been no reports of cultivar specificity among root rotting isolates of $F$. solani on soybean, but variation in aggressiveness among isolates has been demonstrated $(10,11)$.

This research shows that commercial cultivars commonly grown in the Minnesota-North Dakota region are susceptible to root rot caused by $F$. solani. Comparisons among cultivars will, however, need to be made under field conditions with natural inoculum to determine if there are cultivars with some level of field resistance. The low levels of foliar symptoms observed in these experiments indicate that foliar symptoms would not be adequate criteria for making comparisons among cultivars. The fluctuations in temperature and light intensity that occurred in the greenhouse probably contributed to the inconsistent effects of inoculations on disease reactions and the variations in the rankings of cultivars between experiments. For example, within the commercial cultivars evaluated 3 weeks after inoculation, the group grown in the cooler months had high death rates while the group grown in warmer months had low death rates.
Incidence and severity of root rot caused by $F$. solani in the Minnesota-North Dakota region have not been adequately evaluated, but observations and discussions with soybean producers suggest Fusarium root rot may be widespread. The studies by Killebrew et al. (11) suggested that early colonization of soybean by $F$. solani can cause root rot that results in substantial yield reductions. This research also demonstrates that early infection can result in high levels of root rot and plant death. Other root pathogens in this region such as $P$. sojae, $R$. solani, and the soybean cyst nematode in southern Minnesota $(14,15,22)$, may interact with $F$. solani $(3,10,12,18)$, making it difficult to assess the importance of Fusarium root rot. Crops in rotation with

Table 2. Effects of Fusarium solani on root rot at 3 weeks after inoculation of 2-week-old soybean cultivars grown in Minnesota and North Dakota ${ }^{\mathrm{y}}$

\begin{tabular}{lll}
\hline & \multicolumn{2}{c}{ Root rot severity } \\
\cline { 2 - 3 } Cultivar $^{z}$ & Exp A & $\operatorname{Exp~B~}$ \\
\hline
\end{tabular}

North Dakota and northern Minnesota cultivars

Hunter (0) $\quad 5.5 \quad 5.4$

Pioneer $9061(0) \quad 5.5 \quad 5.3$

$\begin{array}{lll}\text { Evans (0) } & 5.4 & 5.3\end{array}$

Dawson (0) $\quad 5.3 \quad 5.0$

NK S-00-88 (00) $\quad 5.3 \quad 5.4$

$\begin{array}{lll}\text { Ozzie (0) } & 5.3 & 5.5\end{array}$

Baker (0) $\quad 5.1 \quad 5.4$

Jacques $009(00) \quad 5.1 \quad 4.9$

McCall (00) $\quad 5.1 \quad 5.6$

Pioneer $9062(0) \quad 5.1 \quad 5.7$

Agassiz (0) $\quad 5.0 \quad 5.3$

$\begin{array}{lll}\text { IS-546 (0) } & 5.0 & 5.3\end{array}$

Lambert (0) $\quad 5.0 \quad 5.2$

NK S-07-80 (0) $\quad 5.0 \quad 5.6$

Sigco $034(00) \quad 5.0 \quad 5.1$

Stine $0450(0) \quad 5.0 \quad 5.2$

Sigco $44(00) \quad 4.9 \quad 5.3$

$\begin{array}{lll}\text { Tracker }(0) & 4.8 & 5.3\end{array}$

Maple Ridge (00) $\quad 4.5 \quad 5.3$

Stine $0380(0) \quad 4.5 \quad 5.3$

Pioneer $9091(0) \quad 4.4 \quad 5.5$

KG-20 (00) $\quad 4.2 \quad 5.2$

$\operatorname{LSD}(P=0.05) \quad 0.5 \quad$ NS

Southern Minnesota cultivars

$\begin{array}{lll}\text { Pioneer 9171 (I) } & 5.2 & 5.0 \\ \text { Hardin (I) } & 5.1 & 4.8 \\ \text { NK S-19-90 (I) } & 5.1 & 5.2 \\ \text { Parker (I) } & 5.1 & 5.0 \\ \text { Pioneer 9111 (I) } & 5.1 & 5.1 \\ \text { Sturdy (II) } & 5.0 & 5.0 \\ \text { Asgrow 1929 (I) } & 4.9 & 5.0 \\ \text { Asgrow 2234 (II) } & 4.9 & 5.0 \\ \text { Bert (I) } & 4.9 & 5.0 \\ \text { Pioneer 9241 (II) } & 4.9 & 5.0 \\ \text { LSD }(P=0.05) & \text { NS } & \text { NS }\end{array}$

y Plants were inoculated in the greenhouse by placing three $F$. solani infested oat kernels on the taproot. Root rot severity was evaluated on a 1-6 scale, which measured the size of lesions or amount of girdling $(1=$ no disease on taproot; $6=$ plant with rotted roots and $75 \%$ of leaves wilted or plant dead).

$\mathrm{z}$ The maturity group of each cultivar is given in parentheses. Cultivars grown in northern Minnesota and North Dakota were tested separately from those grown in southern Minnesota. 
soybean may also influence the severity of Fusarium root rot through their effects on inoculum levels. Three of the isolates used in this research were also pathogenic on Phaseolus vulgaris L. (pinto and navy types), a crop widely grown in the RRV (unpublished data). Melgar and Roy (13) reported that isolates of F. solani causing SDS were not highly pathogenic on $P$. vulgaris.

Prior to the discovery of SDS in the 1970s, little attention was placed on root rot of soybean caused by $F$. solani. Even since that time, there have been few indepth research papers on the disease $(10,11,18)$. The third edition of the Compendium of Soybean Diseases (20) mentions only that $F$. solani was reported to be pathogenic on soybean. Recent research $(10,11,18)$, including the data reported in this paper, indicates that root rot caused by the non-SDS isolates of $F$. solani may be an important soybean disease in North America. Killebrew et al. (10) reported that F. solani form B (FS-B; the type that does not cause SDS) was frequently isolated from soybean roots collected over a fivestate region of the Midwest and southeastern United States. All of the isolates of form B were pathogenic on soybeans. Root rot of soybean caused by isolates of $F$. solani, which do not cause SDS, merits further investigation of its biology and economic effects on soybean production.

\section{LITERATURE CITED}

1. Baker, R. A., and Nemec, S. 1994. Soybean sudden death syndrome: isolation and identification of a new phytotoxin from cultures of the causal agent, Fusarium solani (Abstr.). Phytopathology 84:1144.

2. Baker, R. A., Tarum, J. H., and Nemec, S. 1981. Toxin production by Fusarium solani from fibrous roots of blight-disease citrus. Phytopathology 71:951-954.
3. Datnoff, L. E., and Sinclair, J. B. 1988. The interaction of Fusarium oxysporum and Rhizoctonia solani in causing root rot of soybean. Phytopathology 78:771-777.

4. Doupnik, B., Jr. 1993. Soybean production and disease loss estimates for the North Central United States from 1989 to 1991. Plant Dis. 77:1170-1171

5. Eathington, S. R., Lim, S. M., Nickell, C. D., Pataky, J. K., and Esgar, R. W. 1993. Disease pressure on soybean in Illinois. Plant Dis. 77:1136-1139.

6. French, E. R., and Kennedy, B. W. 1963. The role of Fusarium in the root rot complex of soybean in Minnesota. Plant Dis. Rep. 47:672-676.

7. Jardine, D. J., and Rupe, J. C. 1993. First report of sudden death syndrome of soybean caused by Fusarium solani in Kansas. Plant Dis. 77:1264.

8. Jin, H., Hartman, G. L., Nickell, C. D., and Widholm, J. M. 1996. Characterization and purification of a phytotoxin produced by Fusarium solani, the causal agent of soybean sudden death syndrome. Phytopathology 86:277-282.

9. Kern, H. 1972. Phytotoxins produced by Fusarium. Pages 35-48 in: Phytotoxins in Plant Disease. R. K. S. Wood, A. Ballio, and A. Graniti, eds. Academic Press, New York.

10. Killebrew, J. F., Roy, K. W., and Abney, T. S. 1993. Fusaria and other fungi on soybean seedlings and roots of older plants and interrelationships among fungi, symptoms, and soil characteristics. Can. J. Plant Pathol. 15:139-146.

11. Killebrew, J. F., Roy, K. W., Lawrence, G. W., McLean, K. S., and Hodges, H. H. 1988. Greenhouse and field evaluation of Fusarium solani pathogenicity to soybean seedlings. Plant Dis. 72:1067-1070.

12. McLean, K. S., and Lawrence, G. W. 1993. Localized influence of Heterodera glycines on sudden death syndrome of soybean. J. Nematol. 25:674-768.

13. Melgar, J., and Roy, K. W. 1994. Soybean sudden death syndrome: cultivar reactions to inoculation in a controlled environment and host range and virulence of causal agent. Plant Dis. 78:265-268.

14. Nelson, B. D., Hansen, J. M., and Windels, C. E. 1996. Races of Phytophthora sojae on soybean in the Red River Valley of Minnesota and North Dakota. Plant Dis. 80:104.

15. Nelson, B., Helms, T., Christianson, T., and Kural, I. 1996. Characterization and pathogenicity of Rhizoctonia from soybean. Plant Dis. 80:74-80.

16. Nelson, B. D., and Windels, C. E. 1992 Pathogenicity of Fusarium spp. on soybean in the Red River Valley. (Abstr.) Phytopathology 82:994.

17. Nelson, P. E., Toussoun, T. A., and Marasas, W. F. O. 1983. Fusarium Species: An Illustrated Manual for Identification. Pennsylvania State University Press, University Park. 193 p.

18. Roy, K. W., Lawrence, G. W., Hodges, H. H., McLean, K. S., and Killebrew, J. F. 1989. Sudden death syndrome of soybean Fusarium solani as incitant and relation of Heterodera glycines to disease severity. Phytopathology 79:191-197.

19. Rupe, J. C. 1989. Frequency and pathogenicity of Fusarium solani recovered from soybeans with sudden death syndrome. Plant Dis. 73:581-584.

20. Sinclair, J. B., and Backman, P. A., eds. 1989 Compendium of Soybean Diseases. The American Phytopathological Society, St. Paul, MN. 106 pp.

21. Stephens, P. A., Nickell, C. D., Moots, C. K. and Lim, S. M. 1993. Relationship between field and greenhouse reactions of soybean to Fusarium solani. Plant Dis. 77:163-166.

22. Stienstra, W. C., and MacDonald, D. H. 1990. The soybean cyst nematode. Univ. Minn. Agric. Bull. AG-FO-3935. St. Paul, MN. 6 pp.

23. Warren, H. L., and Kommedahl, T. 1973 Fusarium species in roots and soil associated with monoculture of soybeans in Minnesota. Plant Dis. Rep. 57:912-914.

24. Windels, C. E. 1992. Fusarium. Pages 115128 in: Methods for Research on Soilborne Phytopathogenic Fungi. L. L. Singleton, J. D. Mihail, and C. M. Rush, eds. American Phytopathological Society Press, St. Paul, MN.

25. Yang, X. B., and Rizvi, S. S. A. 1994. First report of sudden death syndrome of soybean in Iowa. Plant Dis. 78:830.

26. Zambolim, L., and Schenck, N. C. 1981. Interactions between a vesicular-arbuscular mycorrhiza and root infecting fungi on soybean. (Abstr.) Phytopathology 71:267. 